\title{
La potestad organizatoria de las Comunidades Autónomas
}

\author{
Bartomeu Colom Pastor \\ Profesor Titular de Derecho Administrativo \\ Universitat de les Illes Balears
}

\begin{abstract}
Sumario: I. AUTONOMÍA IMPLICA AUTOORGANIZACIÓN. - II. INSTITUCIONES DE AUTOGOBIERNO E INSTITUCIONES AUTÓNOMAS PROPIAS. 1. Instituciones de autogobierno. 2. La potestad de autoorganización sobre las instituciones de autogobierno: contenido. 3. Instituciones autónomas propias. III. LA ADMINISTRACIÓN DE LAS COMUNIDADES AUTÓNOMAS Y EL RÉGIMEN ESTATUTARIO DE SUS FUNCIONARIOS PÚBLICOS. 1. Introducción. 2. La doctrina general y de síntesis del Tribunal Constitucional. 3. La doctrina más específica. IV. EVOLUCIÓN DEL EJERCICIO DE LA POTESTAD DE AUTOORGANIZACIÓN. 1. El punto de inicio: los primeros Estatutos. 2. La evolución del ejercicio de la potestad de autoorganización.
\end{abstract}

\section{AUTONOMÍA IMPLICA AUTOORGANIZACIÓN}

La Constitución reconoce el derecho a la autonomía de las nacionalidades y regiones en su artículo 2, idea en la que insiste en sus arts. 137, 143 y 156 referido, este último, a la autonomía financiera.

Una de las múltiples consecuencias jurídicas que derivan de esta proclamación ${ }^{1}$ es la potestad de autoorganización de las Comunidades Autónomas, entendiendo por tal aquella en virtud de la cual una Comunidad Autónoma puede crear y configurar sus instituciones en el marco de la Constitución.

Así lo ha previsto, la Constitución que en su art. 147.2.c) dispone que los Estatutos de autonomía deberán contener «la denominación, organización y sede de las instituciones autónomas propias»

En su artículo 148.1.1. ${ }^{\mathrm{a}}$ señala como primera competencia que pueden asumir las Comunidades Autónomas la «organización de sus instituciones de autogobierno», competencia que por cierto, han asumido todas las Comunidades Autónomas en sus primeros estatutos.

En su art. 149.1.18. ${ }^{a}$ dispone que el Estado tiene competencia exclusiva sobre «el procedimiento administrativo común, sin perjuicio de las especialidades derivadas de la organización propia de las Comunidades Autónomas».

\footnotetext{
1 Junto a las clásicas de capacidad de autodeterminación en el ámbito de sus competencias, capacidad de dictar normas, o la capacidad de influir en las orientaciones políticas del Estado. Véase mi trabajo «Qué es autonomía?» en el libro Veinticinco años de autonomía balear. Estudios jurídicos sobre el autogobierno (1977-2000), Marcial Pons, Madrid, 2001, págs. 61 y ss.
} 
Y en su art. 152.1, párrafo primero, que preceptúa que «en los Estatutos aprobados por el procedimiento a que se refiere el artículo anterior, la organización institucional autonómica se basará en una Asamblea Legislativa, elegida por sufragio universal, con arreglo a un sistema de representación proporcional que asegure, además, la representación de las diversas partes del territorio; un Consejo de Gobierno con funciones ejecutivas y administrativas y un Presidente, elegido por la Asamblea, de entre sus miembros, y nombrado por el Rey, al que corresponde la dirección del Consejo de Gobierno, la suprema representación de la respectiva Comunidad y la ordinaria del Estado en aquélla. El Presidente y los miembros del Consejo de Gobierno serán políticamente responsables ante la Asamblea».

Por último, en su art. 153 c), se refiere a la «administración autónoma» y en su art. 154 a la «administración propia de la Comunidad».

En el mismo sentido lo ha entendido la doctrina jurídico pública sin ningún tipo de fisuras, que ha calificado la potestad de autoorganización de mínimo irreductible de la posición autónoma, como competencia esencial o potestad institucional ${ }^{2}$. En efecto, si la autonomía de las Comunidades Autónomas es política y consiste en la capacidad de dictar normas, en la capacidad de tener políticas propias y diferenciadas de las del Estado en el marco de la Constitución, estas políticas sobre la materia de organización permiten dictar normas reflexivas ${ }^{3}$ que regulen la organización de la propia Comunidad Autónoma, esto es, su autoorganización o la autodisposición sobre su propio aparato.

En la misma línea lo ha entendido el Tribunal Constitucional al concluir que la autonomía de las Comunidades Autónomas es política, que la autonomía es un poder limitado, que la autonomía política es un principio que preside la organización territorial del Estado y que la más genuina expresión del derecho a la autonomía es la capacidad de autoorganizarse libremente.

Efectivamente, en su Sentencia 4/1981, de 2 de febrero, FJ 3, ha proclamado que la autonomía es un poder limitado («la autonomía hace referencia a un poder limitado», autonomía «no es soberanía») y que se ha ejercer «en el marco del ordenamiento», las Comunidades Autónomas son »entes dotadas de autonomía cualitativamente superior a la administrativa». Según la Sentencia 25/1981, de 14 de julio, FJ 3, la autonomía de las Comunidades Autónomas es política ya que «gozan de una autonomía cualitativamente superior a la administrativa que corresponde a los Entes locales, ya que se añaden potestades legislativas y gubernamentales que la configuran como autonomía de naturaleza política». En su Sentencia 13/1992, de 6 de febrero, FJ 7, en la que afirma que la autonomía política de las Comunidades Autónomas y su capacidad de autogobierno, «se

\footnotetext{
2 Por todos véase MuÑoz Machado, S.,Derecho Público de las Comunidades Autónomas, volumen II, Civitas, Madrid, 2007, pág. 77, con citas de C. SCHMITT y J. BURMEISTER.

3 A esta acción reflexiva aunque referida al Estado se refiere la STC 32/1.981, de 28 de julio, en su FJ 5.
} 
manifiesta sobre todo, en la capacidad de elaborar sus propias políticas públicas en las materias de su competencia». Y en las Sentencias 25/1981, de 14 de julio, FJ 3 y 135/1992 de 5 de octubre, FJ.8, ha declarado que la autonomía política es un principio que preside la organización territorial del Estado.

En otra Sentencia, la núm. 227/1988, de 29 de noviembre, FJ 21 c), ha interpretado que, la más genuina expresión del derecho de las nacionalidades y regiones a la autonomía es la capacidad de autoorganizarse libremente, con respeto a los mandatos constitucionales, con estas palabras:

«Es también evidente que este título competencial de Estado no es bastante en ningún caso para legitimar la inserción forzosa en el seno de la Administración autonómica de un órgano jerárquicamente dependiente de la Administración del Estado, pues a ello se opondría de raíz el derecho de todas las nacionalidades y regiones a la autonomía (arts. 2 y 147 de la Constitución), cuya más genuina expresión es la capacidad de autoorganizarse libremente, con respeto a los mandatos constitucionales ${ }^{4} »$.

Y en el FJ 21 c) y 24 de la misma Sentencia, ha proclamado que la regulación básica en materia de régimen jurídico de las Administraciones públicas ha de permitir a las Comunidades Autónomas «adoptar las opciones organizativas que mejor se acomoda a sus necesidades e intereses» y que para el desarrollo de estas normas básicas «las Comunidades Autónomas disponen de un amplio margen de libertad de decisión, que les permite sin duda expresar sus propias opciones políticas sobre la organización administrativa que de ellas depende»

En la Sentencia 50/1999, de 6 de abril, FJ,3 ha declarado que la competencia relativa a la libre organización de la propia de la Administración autonómica ha sido reconocida como «algo inherente a la autonomía». En la número 251/2006, de 25 de julio, FJ 10, ha afirmado que «la potestad autoorganizatoria de las Comunidades Autónomas constituye una manifestación central del principio de autonomía».Y en fin, en la número 35/1982 de 14 de junio, FJ 2, en la que interpreta que las Comunidades Autónomas en el ejercicio de su autonomía, pueden orientar su acción de gobierno en función de una política propia sobre la materia organización, régimen y funcionamiento de sus instituciones de autogobierno.

Todo ello nos permite avanzar que de la autonomía política de las Comunidades Autónomas reconocida por la Constitución en los preceptos que hemos citado, deriva una potestad de autoorganización, que éstas concretan y determinan en el propio Estatuto, que deberá dibujar las líneas maestras o esenciales de la organización de sus instituciones o en palabras de la STC 179/1989, FJ 6:

«La organización de las instituciones de las Comunidades Autónomas viene encomendada por la Constitución al Estatuto de Autonomía, como "norma institucional bá-

4 Idea en la que insiste la Sentencia 48/2003, de 12 de diciembre. 
sica" de cada Comunidad Autónoma [art. 147.1 y 2 c) C.E.]; y será pues el Estatuto de cada Comunidad el que, dentro del respeto a las previsiones constitucionales - como, por ejemplo, las contenidas en el art. 152 C.E-, deba trazar las líneas esenciales a que deberá ajustarse la organización y funcionamiento de la propia Cámara legislativa.»

Precisamente por ello, los Estatutos de Autonomía pueden incluir en relación a la organización de las instituciones autónomas propias, principios rectores y derechos públicos subjetivos (derechos participación, sufragio activo y pasivo y acceso a los cargos públicos) como ha proclamado recientemente el Tribunal Constitucional en su Sentencia 247/2007, de 12 de diciembre, FJ 15 b) ${ }^{5}$.

En consecuencia se ha dicho que, al tramitar los Estatutos, las Cortes Generales controlan esta potestad autoorganizatoria ${ }^{6}$

Pero las determinaciones de los Estatutos se pueden desplegar en las leyes que se dicten en desarrollo de los mismos, ya que no existe una reserva estatutaria absoluta frente a las leyes de las Comunidades Autónomas que pueden desarrollar a los Estatutos en materia de organización de las instituciones autónomas propias $^{7}$.

Analizar el alcance y límites de estos poderes de autoorganización de las Comunidades Autónomas constituye el objetivo del presente trabajo.

\section{INSTITUCIONES DE AUTOGOBIERNO E INSTITUCIONES AUTÓNOMAS PROPIAS}

\section{Instituciones de autogobierno}

Como ya hemos señalado, la totalidad de Comunidades Autónomas por lo menos en los primeros estatutos han asumido el título competencial descrito en el art. 148.1.1. ${ }^{a}$ de la Constitución, esto es, la organización de las instituciones de autogobierno. Pero, ¿qué hay que entender por institución de autogobierno? En mi opinión, autogobierno es sinónimo de autonomía política y por ello son las instituciones que concentran los poderes de dirección política o, en palabras del Tribunal Constitucional, «órganos destinados a servir la acción política de la Comunidad Autónoma ${ }^{8} \gg$. Un concepto restrictivo de institución de autogobierno reduciría éstas a las instituciones descritas en el art. 152 de la Constitu-

\footnotetext{
5 Doctrina que ha reiterado en la Sentencia 249/2007, de 13 de diciembre, FJ 4 y 5.

6 Gil Robles y Gil Delgado J. M. a , con la colaboración de Gil-Robles CASANUEVA,L, al comentar el art. 153 de la Constitución, en Comentarios a la Constitución Española de 1978, tomo XI, Edersa, Madrid, 1999, pág. 435.

7 STC 89/1984, FJ 7.

8 STC 35/82, FJ 3.
} 
ción, es decir, la Asamblea Legislativa, el Consejo de Gobierno y el Presidente ${ }^{9}$. Pero ello no casaría con la definición que hemos dado de instituciones que encarnan la autonomía política o de instituciones que concentran los poderes de dirección política de las comunidades autónomas. Por todo ello hay que entender como institución de autogobierno cualquiera otra incorporada a través del Estatuto u otra norma posterior de la Comunidad Autónoma que materialice la autonomía política o que concentre poderes de dirección política de la Comunidad Autónoma.

Hay abundante jurisprudencia del Tribunal Constitucional sobre el concepto de institución de autogobierno que nos permite trazar su evolución. En efecto, inicialmente el Tribunal Constitucional ha entendido por instituciones de autogobierno las descritas en el art. 152.1 de la Constitución y, además, las descritas como tales en los propios Estatutos; en otras palabras, la organización política fundamental de las Comunidades Autónomas ${ }^{10}$. Este es el caso de la Sentencia 76/1983, FJ 38, en la que podemos leer que:

«(...)no puede otorgarse a la expresión "instituciones de autogobierno" un alcance mayor que el que deriva de la Constitución (artículo 152.1) y de los propios Estatutos (...).»

Idea en la que insiste la Sentencia 132/1989, FJ 21, al proclamar que:

«Según reiterada doctrina de este Tribunal, tal título [organización de sus instituciones de autogobierno] se extiende exclusivamente a la organización política fundamental de la Comunidad Autónoma, sin afectar a la simple organización administrativa(STC 76/1983, fundamento jurídico 38), ni en concreto, a las "Organizaciones Profesionales Agrarias".»

Nótese que nos referimos a un concepto que incluye las instituciones del art. 152.2 de la Constitución y además las instituciones que regulen como tales los propios Estatutos ${ }^{11}$, esto es: las instituciones políticas fundamentales que los estatutos consideren como instituciones de autogobierno aunque no sean la Asamblea legislativa, el Consejo de Gobierno y el Presidente.

Pero esta inicial interpretación se ha visto ampliada por otros pronunciamientos en los que se extienden las instituciones consideradas de autogobierno a las que puedan crear las Comunidades Autónomas, que pueden suplir o sustituir a las instituciones del Estado y de esta forma coadyuvar o favorecer el au-

\footnotetext{
9 Según el FJ 8 de la STC 2006/222, de 6 de julio, los presidentes de las Comunidades Autónomas no se integran en las Administraciones autonómicas.

10 En palabras de la S.T.C. 132/1989, F.J 21.

11 Como puso de manifiesto CARro Fernández-VAlmayor ,J. L., al comentar el art. 27 del Estatuto de autonomía gallego y la STC 76/1983, FJ 38, en Cometarios al Estatuto de Autonomía de la Comunidad Autónoma de Galicia, MAP, Madrid, 1991, pág. 336.
} 
togobierno y para servir su acción política. Este es el caso de los órganos superiores consultivos de las comunidades autónomas, los defensores del pueblo de las comunidades o los tribunales de cuentas de éstas. Así lo ha entendido el Tribunal Constitucional en su Sentencia 35/1982, FJ 2 y 3, al proclamar que:

«Estas instituciones [de autogobierno] son primordialmente las que el mismo Estatuto crea y que están por ello constitucionalmente garantizadas, pero no sólo ellas, pues la Comunidad puede crear otras en la medida en que lo juzgue necesario para su propio autogobierno.» ${ }^{12}$

De esta manera, se consideran instituciones de autogobierno, los consejos consultivos u órganos superiores consultivos de las Comunidades Autónomas, esto es: los órganos consultivos equivalentes al Consejo de Estado de las Comunidades Autónomas ${ }^{13}$, el Consejo de Relaciones Laborales del País Vasco ${ }^{14}$, o el Consejo de Cuentas de Galicia ${ }^{15}$. Nótese que todas de estas instituciones, se justifica con base a la competencia sobre organización de las instituciones de autogobierno de las Comunidades Autónomas. Lo mismo sucede con el Consejo de Relaciones Laborales del País Vasco, que no encuentra su amparo en la competencia en materia de legislación laboral (que no lo contempla y que es una competencia de simple ejecución ${ }^{16}$ de la Comunidad Autónoma del País Vasco) sino en la competencia sobre organización de las instituciones de autogobierno ${ }^{17}$.

En cambio, no puede considerarse un órgano creado por la Comunidad Autónoma en virtud de esta competencia la Sección de Enjuiciamiento contable creada por la Ley catalana de la Sindicatura de Cuentas ${ }^{18}$, o los servicios administrativos ${ }^{19}$.

La tipología de estos órganos es variada: se trata a veces de órganos con relevancia estatutaria (aunque pueden no serlo) pueden estar adscritos a los Parlamentos de las Comunidades o no y pueden incluso consistir en órganos relevantes de la Administración de la comunidad y referirse a competencias exclusivas, compartidas o incluso de ejecución.

\footnotetext{
12 Idea en la que insiste la STC 165/1986, FJ 6.

13 STC 204/1992, FJ 4 y 5.

14 STC 35/1982, FJ 2 y 3. Una institución, por cierto, creada por Ley sobre una competencia ejecutiva de la Comunidad Autónoma.

15 STC18/1991, FJ 5.

16 Como puso de manifiesto GARCÍA DE ENTERRÍA, E, Estudios sobre autonomías territoriales, Civitas, Madrid, 1985, pág. 185.

17 Sobre la referida institución y la STC 35/1982, de 14 de junio véase el artículo de Antonio-Vicente SEMPERE NAVARRO, «El consejo de relaciones laborales como institución autonómica» Civitas, Revista española del Derecho del Trabajo, núm. 9, enero-marzo de 1982, pág. 597 y ss.

18 STC 187/1988, FJ 5.

19 STC 186/1988, FJ 4.
} 
Pero, el concepto amplio de institución de autogobierno,¿incluye a la Administración propia de las Comunidades Autónomas, su personal y sus servicios? Este concepto no incluye, en mi opinión, a la Administración propia de las Comunidades Autónomas ${ }^{20}$, su personal y sus servicios. En efecto, si por institución de autogobierno hay que entender la que ejerce la autonomía política o los poderes de dirección políticos habría que concluir que la Administración propia de las Comunidades Autónomas no es una institución de autogobierno; más bien está dirigida por una institución de este carácter que es el Gobierno de la Comunidad que tiene encomendada la función de dirección política.

Esta posición es la que ha mantenido el Tribunal Constitucional desde la Sentencia 76/1983, FJ 38, en la que proclama que la potestad organizatoria referida a la Administración propia de la comunidad y sus funcionarios es una competencia compartida que no deriva del título organización de sus instituciones de autogobierno, con esta palabras:

«El artículo 149.1.18 de la Constitución reconoce al Estado competencia exclusiva para dictar las bases del régimen jurídico de las Administraciones públicas y del régimen estatutario de sus funcionarios. De ello deriva una doble competencia estatal en materia de función pública: $1{ }^{a}{ }^{a}$ ) competencia para regular los aspectos básicos de la situación personal de los funcionarios públicos; es decir, de la denominada relación de servicio, contenido indiscutible del régimen estatutario, y $2 .^{a}$ ) competencia para regular los aspectos esenciales de la organización de la burocracia de las Administraciones públicas, pues la expresión "régimen jurídico" contenida en el precepto constitucional no se refiere exclusivamente al procedimiento y al régimen de recursos, como ha señalado este Tribunal Constitucional en su sentencia 32/1981 de 28 de julio, y ha de entenderse incluida también en ella la regulación básica de la organización de todas las Administraciones públicas.

Los recurrentes sostienen que tal competencia de carácter organizativo corresponde a las Comunidades Autónomas al haber asumido éstas en sus Estatutos, con carácter exclusivo, la competencias en materia de organización y régimen de sus instituciones de autogobierno. Pero la potestad organizatoria que corresponde a las Comunidades

\footnotetext{
20 La doctrina no administrativa está dividida. Así, mientras que para algunos autores la Administración propia de la Comunidad sería una institución de autogobierno: MuÑOZ MACHADO, S., Derecho Público... op. cit., pág. 68; FonT I Llovet, T., en el libro El sistema jurídico de las Comunidades Autónomas, Tecnos, Madrid, 1985, pág. 290; LóPEZ RAMÓN, F., al comentar el art. 35.1.1 del Estatuto de autonomía aragonés, en Comentarios al Estatuto de Autonomía de la Comunidad Autónoma de Aragón, MAT, Instituto de Estudios de Administración Local, Madrid, 1985, pág. 365 y CASTILlo BlANCO, F.A. al comentar el art. 148.1.1. a de la Constitución, en Comentarios a la Constitución Española de 1978, tomo XI, Edersa, Madrid, 1999, pág. 169. Para otros, no lo sería: de esta manera, no sería una institución política para SoSA WAGNER, F., con la colaboración de RICARDO CABALLERO, al comentar el art. 10. 1.a) del Estatuto de autonomía asturiano, en Comentarios al Estatuto de Autonomía de la Comunidad Autónoma del Principado de Asturias, MAP, Instituto de Estudios de Administración Local, Madrid, 1987, págs. 83 y 84; no constituiría propiamente un elemento organizativo institucional a efectos del art. 152 de la Constitución para BASSOLS COMA, M., «Los órganos ejecutivos de las Comunidades Autónomas: Presidencia y Consejo de Gobierno", REDA, 40/41, 1984, pág. 106; y no sería una institución de autogobierno para CARRo FERnÁndeZ-VALMAYOR, J. L., Comentarios..., op, cit., págs. 337 y 338, y «Sobre la potestad autonómica de autoorganización», REDA, núm. 71, págs. 321 y 322 .
} 
Autónomas para ordenar sus servicios, de los que el personal es uno de sus elementos integrantes, no deriva de la norma estatutaria que contiene dicha competencia, pues no puede otorgarse a la expresión "instituciones de autogobierno" un alcance mayor que el que deriva de la Constitución (artículo 152.1) y de los propios Estatutos - Asamblea legislativa, Consejo de Gobierno y Presidente-, sino de la competencia por ellas asumida respecto a la organización de sus propias Administraciones y en esta materia cada Comunidad Autónoma ha de respetar, en cualquier caso, las bases que, de acuerdo con lo establecido en el artículo 149.1.18 de la Constitución, corresponde fijar al Estado.»

Idea en la que insiste la Sentencia 165/1986, FJ 6 :

«No cabe entender que la potestad de autoorganización pueda extenderse hasta abarcar en su seno la organización de la respectiva Administración pública y el régimen estatutario de sus funcionarios.»

Y en la Sentencia 132/1989, FJ 21, que asevera que según reiterada doctrina del Tribunal el título previsto en el art. 148.1.1. ${ }^{\mathrm{a}}$ de la Constitución «se extiende exclusivamente a la organización política fundamental de la Comunidad Autónoma, sin afectar a la simple organización administrativa (STC 76/1983, fundamento jurídico 38), ni en concreto, a las "Organizaciones Profesionales Agrarias".»

\section{La potestad de autoorganización sobre las instituciones de autogobierno: contenido}

La potestad de autoorganización de las Comunidades Autónomas sobre instituciones de autogobierno es máxima ya que no puede verse afectada por el título competencial del Estado previsto en el art. 149.1.18. a de la Constitución (bases del régimen jurídico de las Administraciones públicas y del régimen estatutario de sus funcionarios). Así lo ha entendido el Tribunal Constitucional tempranamente en la Sentencia 32/1981, FJ 5, al proclamar que:

«Tampoco puede afirmarse sin más que la expresión "régimen jurídico de las administraciones públicas" abarque en "puridad todo el Derecho Administrativo, cuya clave es la sumisión de la Administración al Derecho" y no porque de esta afirmación pudiera concluirse que tiene el estado competencia para dictar bases sobre la organización de la Generalidad, pues manifiestamente la potestad para organizar las propias instituciones de autogobierno que consagra el artículo 9.1 del Estatuto de Autonomía [catalán] no podría verse en modo alguno afectada por ella»

Esta libertad de configuración organizativa significa que las instituciones de autogobierno tampoco deben adecuar su estructura, funcionamiento y organización a la de los órganos correspondientes del Estado, no siendo de aplicación supletoria las normas del Estado que regulan la organización y funcionamiento de estos órganos. Así lo ha proclamado la Sentencia 179/1989, FJ 6, que concluye lo siguiente:

«Pero no es en modo alguno exigible, en virtud de los mandatos constitucionales, que las instituciones legislativas de las Comunidades Autónomas deban adecuar su 


\section{LA POTESTAD ORGANIZATORIA DE LAS COMUNIDADES AUTÓNOMAS}

estructura, funcionamiento y organización a las correspondientes de las Cortes Generales, ni que deban aplicarse a las Cámaras legislativas de las Comunidades Autónomas, en forma directa o supletoria, las normas constitucionales que regulen la organización y funcionamiento de las Cortes Generales, entre ellas el art. 79.2 CE.»

Por tanto, puede hablarse sin ambages de una verdadera y auténtica competencia exclusiva de las Comunidades Autónomas reconocida por el art. 148.1.1. ${ }^{\mathrm{a}}$ y asumida por casi todos los Estatutos de Autonomía con un triple contenido que les permite determinar o configurar la organización o estructura de las instituciones de autogobierno, el procedimiento y funcionamiento interno de estas instituciones y que tiene su proyección en la regulación del estatuto de los cargos públicos de las Comunidades Autónomas. Vale la pena analizarlo:

a) Determinar o configurar la organización o estructura de las instituciones de autogobierno.

La primera facultad general en la que se despliega la potestad de autoorganización de las instituciones de autogobierno, consiste en configurar o determinar la organización o estructura de estas instituciones ${ }^{21}$. Dicha facultad se desarrolla, a su vez, en una serie de atributos entre los que destacan el de distribuir las competencias entre los diferentes órganos de la Comunidad y por ello determinar el órgano o institución que ha de ejercer la competencia ${ }^{22}$; fijar el rango de las normas que tienen que realizar dicha atribución, así como el rango de las normas a través de la cuales haya de ejercerse dicha competencia ${ }^{23}$. Todo ello siempre respetando el propio Estatuto, que se configura como uno de los límites de la autoorganización ${ }^{24}$.

Por ello, es contrario a la autoorganización de las Comunidades Autónomas que el Estado determine en el art. 7.4 de la Ley 7/1984, de 31 de marzo de 1984, del Fondo de Compensación Interterritorial que la sustitución de las obras que integran la relación de proyectos de inversión que componen el Fondo deba ser aprobada por el Consejo de Gobierno de la Comunidad Autónoma cuando dicho proyecto corresponda a una competencia transferida a esa Comunidad Autónoma ${ }^{25}$.

En cambio, entiende el Tribunal Constitucional, que no vulnera el título competencial analizado la normativa estatal que se limita a seleccionar las asociaciones, que en caso de que la previsión participativa sea establecida por la

\footnotetext{
21 A esta facultad se refiere la STC 183/1988, F.J 6 y la STC 179/1989, FJ 6.

22 STC 183/1988, FJ 6 y 56/1990, FJ 26.

23 STC 56/1990, FJ 26 y 62/1990 FJ 10.Regla general que admite excepciones como las contempladas en las referidas sentencias en las que la propia Constitución en el art. 152.2 remitía a lo previsto en la Ley Orgánica del Poder Judicial.

24 STC 35/1982, FJ 3.

25 STC 183/1988, FJ 6.
} 
Comunidad, deben ostentar la representación institucional de los intereses generales de los empresarios ${ }^{26}$; las normas del Estado que establecen los requisitos para alcanzar la condición de sindicato más representativo ante órganos comunitarios $^{27}$; o la disposición del Estado que regula la Comisión Consultiva Nacional de Convenios Colectivos ${ }^{28}$.

Más limitados son los poderes de autoorganización de las comunidades autónomas cuando se ejercen sobre competencias materialmente ejecutivas, como es el caso del Consejo de Relaciones laborales del País Vasco al que ya hemos aludido, ya que en este supuesto no «puede encomendarles el ejercicio de competencias que la propia Comunidad Autónoma no tiene, ni atribuirles facultades que corresponden a los órganos previstos en la legislación laboral, ni en ningún caso encomendarles tareas que impliquen directa o indirectamente violación o desconocimiento de tal legislación» 29 .

b) Configurar el procedimiento y funcionamiento interno de estas instituciones.

Estos poderes de autoorganización hacen referencia, de otro lado al funcionamiento ${ }^{30} \mathrm{y}$ al procedimiento interno de las mismas. En consecuencia, es contrario a la autoorganización de las Comunidades Autónomas y a su autonomía financiera proclamada en el art.156.1 de la Constitución, la regulación por parte del Estado de extremos del procedimiento interno de las Comunidades Autónomas de aprobación del uso de recursos propios, en particular el informe favorable del Consejo General del Poder Judicial previo a la aprobación de los recursos propios de las Comunidades Autónomas destinados a la Administración de Justicia ${ }^{31}$, y la obligación de que la solicitud del dictamen del Consejo de Estado sea cursada a través del Ministerio de Administración Territorial ${ }^{32}$.

c) Regular el estatuto de los cargos públicos de las Comunidades Autónomas.

De otro lado, estos poderes de autoorganización tienen su proyección en los cargos públicos. Las Comunidades Autónomas pueden regular el estatuto de los consejeros con las limitaciones derivadas de las competencias reservadas al

\footnotetext{
26 STC 57/1989, FJ 1.

27 STC 98/1985, FJ 15 y 16.

28 STC 17/1986, FJ 2.Tres son los argumentos básicos de la Sentencia: el carácter facultativo de la consulta, el que la Comisión constituye un instrumento de colaboración del Estado con las Comunidades Autónomas y el que no impide a éstas establecer y recurrir a sus propios órganos consultivos.

29 STC 35/1982, FJ 3.

30 STC 179/1989, FJ 6.

31 STC 56/1990, FJ 12.

32 STC 214/1989, FJ 17.
} 
Estado $^{33}$.Por ello, el art. 22 de la Ley Orgánica 8/1984, de 26 de diciembre, contra la actuación de bandas armadas y elementos terroristas y de desarrollo del artículo 55.2 de la Constitución, al establecer una suspensión automática en el ejercicio de la función o cargo público de cualquier persona procesada por un delito comprendido en la referida Ley Orgánica, afecta a los cargos públicos de las Comunidades Autónomas, a los miembros de sus Parlamentos y al resto de sus funcionarios, y por ende afecta a la organización de las instituciones de autogobierno ${ }^{34}$.

El título competencial analizado permite establecer las precedencias entre autoridades de la misma Comunidad Autónoma, aunque no permite a éstas establecer la precedencia relativa entre sus órganos y autoridades y los del Esta$\mathrm{do}^{35}$. No puede considerarse como expresión de este título competencial el fuero jurisdiccional penal de los miembros del Consejo de Gobierno ya que constituye uno de los objetos de regulación de la legislación procesal, atribuida con carácter exclusivo al Estado (art. 149.1.6) ${ }^{36}$.

Esta potestad de autoorganización máxima tiene su límite en la propia Constitución. De esta manera, el refrendo del nombramiento del Presidente de la Comunidad corresponde al Presidente del Gobierno y no al Presidente del Parlamento Vasco, porque así lo prevé la Constitución en sus arts. 56.3 y 64.137.

\section{Instituciones autónomas propias}

De entrada, señalar que en mi opinión, la cláusula del art. 147.2. c) «organización de las instituciones autónomas propias» es más amplia que la del art. 148.1.1. " «organización de sus instituciones de autogobierno», ya que además de las instituciones de autogobierno puede incluir cualquier institución autónoma propia que no lo sea, esto es, cualquier institución autónoma propia designada como tal por el Estatuto, aun cuando no sea institución de autogobierno. En conclusión, si bien todas las instituciones de autogobierno son instituciones propias de las Comunidades Autónomas no todas las instituciones propias son instituciones de autogobierno. Por ello, la interpretación del Tribunal Constitucional respecto a las instituciones de autogobierno no es trasladable siempre a las instituciones autónomas propias ni las comunidades autónomas tienen idénticos poderes de autoorganización sobre éstas, aunque el máximo intérprete de la Constitución en multitud de sentencias invoca los dos preceptos ${ }^{38}$.

\footnotetext{
33 STC 159/1991, FJ 4.

34 STC 199/1987, FJ 1.

35 STC 12/1985, FJ 3 y 38/1982 FJ 2.

36 STC 159/1991, FJ 4.

37 STC 5/1987, de 27 de enero, FJ 2,3, 5,6 y 7.

38 Entre ellas la 179/1989, FJ 3 y 6; 56/1990, FJ 12 y la 204/1992 FJ 4.
} 


\section{LA ADMINISTRACIÓN DE LAS COMUNIDADES AUTÓNOMAS Y EL RÉGIMEN ESTATUTARIO DE SUS FUNCIONARIOS PÚBLICOS}

\section{Introducción}

A) Los poderes de autoorganización de las Comunidades Autónomas sobre su administración propia son más limitados que sobre las instituciones de autogobierno, por distintos motivos:

a) Porque los principios proclamados en el art. 103 de la Constitución, aunque están referidos a la Administración del Estado afectan a todas las Administraciones públicas por estar recogidos en el art. 3 de la Ley 30/1992, de 26 de noviembre, de Régimen Jurídico de las Administraciones públicas y del Procedimiento Administrativo Común.

b) Porque como ya hemos señalado si bien la Administración propia es una institución propia de cada Comunidad Autónoma no es una institución de autogobierno.

c) Por el título competencial del Estado previsto el art. 149.1.18. ${ }^{\mathrm{a}}$, de la Constitución esto es, por las bases del régimen jurídico de las administraciones publicas y del régimen estatutario de los funcionarios públicos. Como es sabido con ocasión de la impugnación de la Ley por la que se regula la transferencia urgente y plena de las Diputaciones catalanas a la Generalidad en la que se discutía si por bases del régimen jurídico de las administraciones públicas había que entender sólo el procedimiento y el régimen de recursos (tesis defendida por la Generalidad en base al dictamen de la Comisión Jurídica Asesora de la Generalidad de Cataluña de agosto de 1979) el Tribunal Constitucional, en su fundamental Sentencia 32/1981, de 28 de julio, FJ 5, sentó el criterio que también incluía la organización de las Corporaciones locales y sus competencias.

Esta es la tesis central de la fundamental STC 76/1983, FJ 38 ya transcrita, al proclamar que «la potestad organizatoria que corresponde a las Comunidades Autónomas para ordenar su servicios, de los que el personal es uno de sus elementos integrantes, no deriva de la norma estatutaria que contiene dicha competencia, (...) sino de la competencia por ellas asumida respecto a la organización de sus propias Administraciones y en esta materia cada Comunidad Autónoma ha de respetar, en cualquier caso, las bases que, de acuerdo con lo establecido en el artículo 149.1.18 de la Constitución, corresponde fijar al Estado.»

d) Porque las competencias exclusivas del Estado son un límite a la autoorganización de las Comunidades Autónomas. Basta ver las Sentencias del 
Tribunal Constitucional 150/1998, FJ 2 y 175/1990, de 1 de julio, FJ2, que en base a la competencia exclusiva sobre la Administración de Justicia declara en la primera la inconstitucionalidad de un precepto de una ley autonómica que atribuía la Presidencia de las Comisiones Locales de Concentración parcelaria al Juez de Primera Instancia a cuya jurisdicción correspondiera la zona, y, en la segunda Sentencia, proclama que la Comunidad Autónoma de Galicia carece de competencia para integrar a Magistrados de las Audiencias Provinciales en los jurados Provinciales de Clasificación de Montes Vecinales, con el argumento de que «debe ser el Estado, titular exclusivo de la competencia, quien pondere qué funciones gubernativas pueden realizar aquéllos sin que por tal motivo la exclusividad y la independencia de la función jurisdiccional queden menoscabadas».

B) La potestad de autoorganización de las Comunidades Autónomas sobre su administración es superior a la que tienen los demás entes dotados de autonomía administrativa, por cuanto:

a) Aunque las administraciones propias no son instituciones de autogobierno, pertenecen a las Comunidades Autónomas que gozan de importantes poderes de autoorganización también sobre su administración, derivados precisamente de su autonomía política, del derecho a la autonomía proclamado en el art 2 de la Constitución.

b) La administración de las Comunidades Autónomas, calificada de administración propia por la Constitución art. 154, es una institución propia de la Comunidad Autónoma.

c) La misma Constitución califica a esta administración de administración autónoma, art.153 c).

d) La norma fundamental salva las facultades de autoorganización de la Comunidad incluso cuando describe la competencia estatal sobre procedimiento administrativo común ya que lo hace «sin perjuicio de las especialidades derivadas de la organización propia de las Comunidades Autónomas» (art.149.1.18) como ha puesto de manifiesto CLIMENT BARBE$\mathrm{RA}^{39}$. Pues bien, en mi opinión, esta preservación de la organización propia de la Comunidad Autónoma alcanza a su Administración que es autónoma según el art.153 c) de la norma fundamental.

e) Esta potestad se ejercerá respecto de las competencias exclusivas, de las competencias compartidas (esto es de desarrollo legislativo y ejecución)

39 En su artículo, «Potestad de autoorganización y procedimiento administrativo de las Comunidades Autónomas», en el libro Gobierno y Administración en la Constitución, Volumen I, Dirección General del Servicio Jurídico del Estado, Instituto de Estudios Fiscales, Madrid, 1988, pág. 412. 
e, incluso de las competencias de ejecución de las Comunidades Autónomas ya que en la función ejecutiva reservada a las Comunidades Autónomas debe entenderse incluida la potestad de dictar reglamentos de organización, cual es el caso del reglamento que reguló el Registro de Convenios Colectivos de Trabajo del País Vasco ${ }^{40}$, toda vez que como ha proclamado el máximo intérprete de la Constitución en su Sentencia 243/1994:

«Es cierto que, cuando una Comunidad Autónoma posee las competencias ejecutivas sobre una determinada materia, tiene también, en virtud de sus potestades organizatorias y de la libre fijación de su política ejecutiva, la competencia para dictar las normas de organización y funcionamiento interno de los servicios administrativos a los que encomienda la realización de esta ejecución, sin perjuicio, naturalmente, de las competencias básicas que el art. 149.1.18 de la Constitución atribuye al Estado. Como ha reiterado este Tribunal, en la función ejecutiva reservada a las Comunidades Autónomas debe entenderse incluida la potestad de dictar disposiciones o reglamentos internos de organización de los correspondientes servicios administrativos.»

Doctrina que el máximo interprete de la Constitución ha reiterado respecto del Jurado territorial de expropiación forzosa de la Comunidad de Madrid ${ }^{41}$.

f) Todo ello implica que la potestad de autoorganización de las Comunidades Autónomas sobre su Administración propia es superior a la de los demás entes que gozan de autonomía.

En definitiva, si por un lado resulta que el Estado tiene competencia sobre las bases el régimen jurídico de las administraciones públicas y sobre del régimen estatutario de los funcionarios públicos, pero estas administraciones son más autónomas que otras, todo ello implica que las bases del Estado habrán de ser de menor extensión o intensidad que las referidas a las demás Administraciones públicas.

g) El Estado ha regulado formalmente con parquedad la materia referida a la Administración de la Comunidad Autónoma ya sea con carácter general para todas las Administraciones Públicas en la Ley de Régimen Jurídico de las Administraciones Públicas del Procedimiento Administrativo Común, ya sea con carácter particular para las Administraciones propias de las Comunidades en la Ley del Proceso Autonómico, aunque esta regulación inicial se ha visto incrementada gracias la concepción material

\footnotetext{
40 STC 18/1982, de 4 de mayo, FJ 2, 4 y 5. Y ha reiterado el Alto Tribunal en las Sentencias 39/1982,76/1983, 249/1988 y 243/1994, FJ 4 y puso de manifiesto la doctrina . Por Todos véase a GARCía DE ENTERRÍA, E, Estudios sobre autonomías territoriales, Civitas, Madrid, 1985, págs. 184 y 185.

41 En las Sentencias 251/2006, de 25 de julio, FJ 5 c) y 6; 313/2006, de 8 de noviembre, FJ 3; y 314/2006, de 8 de noviembre, FJ 3.
} 
de bases, esto es, cuando el Estado aduce el título competencial bases del régimen jurídico de las Administraciones públicas y del régimen estatutario de sus funcionarios en una controversia con una Comunidad Autónoma respecto a una norma distinta y el Tribunal Constitucional proclama que el precepto en cuestión es básico.

h) La mayoría de estatutos suelen contener preceptos específicos en orden a la potestad organizatoria de la Comunidad Autónoma, esto es, a la creación y estructuración de la Administración pública propia de la Comunidad Autónoma.

C) Aún partiendo de la hipótesis según la que la administración de las Comunidades Autónomas es una institución de autogobierno, distinta de la mantenida en este trabajo, una parte de la doctrina había llegado a soluciones parecidas. Así MUÑOZ MACHADO ${ }^{42}$ había llegado a la conclusión de que el art. 149.1.18 atribuye al Estado competencias organizativas genéricas en relación con todas las Administraciones Públicas de intensidad distinta según se emplee en relación con las Corporaciones locales o con las Comunidades Autónomas; que las bases del régimen jurídico de las administraciones públicas y del régimen estatutario de los funcionarios públicos sólo pueden fijar los principios generales y comunes «de la disciplina jurídica del las Administraciones autónomas y de la relación de empleo de los funcionarios que las sirven», y que el Estado no puede, al utilizar este titulo, para imponer medidas organizativas concretas. Por su parte, FONT I LLOVET ${ }^{43}$ había propugnado una amplia potestad de autoorganización de las comunidades autónomas sobre su administración propia limitada únicamente por unas bases del régimen jurídico estatales de todas las Administraciones públicas que sólo de forma indirecta llegasen a tener consecuencias organizativas.

\section{La doctrina general y de síntesis del Tribunal Constitucional}

El Tribunal Constitucional en numerosas sentencias ha ido decantado una doctrina general rica y matizada sobre los poderes de autoorganización de las Comunidades Autónomas sobre su administración propia, caracterizada por dar un contenido competencial mínimo a cada uno de los títulos competenciales en aparente conflicto, y respetar un ámbito de autodisposición de las Comunidades Autónomas sobre su administración propia, cuya resolución central es la fundamental Sentencia 50/1999, que ha recogido en lo sustancial las conclusiones a las que había llegado la mejor doctrina, el reconocimiento de una competencia autoorganizatoria exclusiva, la proscripción de medidas organizativas y la regulación de una bases principiales y comunes a todas las Administraciones públicas.

42 Vid. Derecho Público... op. cit., pág. 71.

43 Vid. El sistema jurídico..., op. cit., pág. 292. 
Según esta doctrina, la potestad de autoorganización de las Comunidades sobre su Administración, deriva de su autonomía, pero esta potestad tiene grados e intensidades diferentes. Por ello puede distinguirse por lo menos tres círculos: un núcleo duro o competencia exclusiva relativa de las Comunidades Autónomas; una zona de competencia compartida en la que las bases estatales no pueden ser detalladas; y a su vez estas bases tendrán menor extensión e intensidad cuando se refieran a aspectos meramente organizativos internos que no afecten directamente a la actividad externa de la Administración y de los administrados y más extensión en aquellos aspectos en los que se da esta afectación. Vale la pena analizar estos tres círculos:

\section{a) La competencia exclusiva relativa de las Comunidades Autónomas}

En efecto, las Comunidades Autónomas tienen competencia exclusiva de autoorganización de su Administración propia. Esta competencia que es inherente a su autonomía, les permite crear su propia administración, crear, modificar o extinguir órganos, unidades o entidades, esto es, conformar libremente la estructura orgánica de su aparato administrativo. El Estado debe abstenerse de intervenir en este ámbito. Así se expresa la STC 50/1999, FJ 3:

«Respecto de la competencia relativa a la libre organización de la propia Administración autonómica, que con carácter de competencia exclusiva alegan las dos Comunidades Autónomas, debe advertirse que esta competencia, que efectivamente ha sido reconocida por este Tribunal en diversas ocasiones como algo inherente a la autonomía (STC 227/1988, fundamento jurídico 24) en tanto que competencia exclusiva tiene como único contenido la potestad para crear, modificar y suprimir los órganos, unidades administrativas o entidades que configuran las respectivas Administraciones autonómicas o dependen de ellas (SSTC) 35/1982, 165/1986, 13/1988 y 27/1988). Hemos declarado que <conformar libremente la estructura orgánica de su aparato administrativo $>$ (STC 165/1986, fundamento jurídico 6. ${ }^{\circ}$ ), establecer cuales son <los órganos e instituciones $>$ que configuran las respectivas Administraciones (STC 35/ 1982, fundamento jurídico $2 .^{\circ}$ ), son decisiones que corresponden únicamente a las Comunidades Autónomas y en consecuencia el Estado debe abstenerse de cualquier intervención en este ámbito (STC 227 /1988 y “a sensu contrario” STC 13/1988.»

Esta competencia permite a las Comunidades Autónomas organizar su planta, la atribución y el reparto de las competencias entre órganos y servicios, e impide al Estado imponer medidas de organización administrativa, o en palabras de la STC 186/ 1988, FJ 4:

«Finalmente, el promotor de los conflictos considera invalidada la potestad autoorganizativa atribuida a la Comunidad Autónoma por el art.10.2 del Estatuto de Autonomía del País Vasco, "en su vertiente administrativa”. El art. 10.2 del Estatuto de Autonomía del País Vasco incluye entre las competencias exclusivas de la Comunidad Autónoma la "organización, régimen y funcionamiento de las instituciones de autogobierno". A este respecto debe señalarse que si bien el art. 10.2 del Estatuto de Autonomía del País 


\section{LA POTESTAD ORGANIZATORIA DE LAS COMUNIDADES AUTÓNOMAS}

Vasco se limita en su redacción a mencionar las instituciones de autogobierno, que son la Asamblea Legislativa, el Consejo de Gobierno y el Presidente, sin que bajo esa denominación puedan incluirse los servicios de la Comunidad - STC 76/1983, fundamento jurídico 38 - la competencia en esta materia del País Vasco, quedaría afectada si el Estado, haciendo uso de sus competencias en materia de Administración Pública impusiese medidas de organización administrativa a la Comunidad Autónoma-STC 32/1981, fundamento jurídico $5 .^{\circ}-$ Corresponde en todo caso, al País Vasco, sea cual fuere la norma habilitante, la organización de su planta administrativa y el reparto de los cometidos de la Comunidad Autónoma entre los órganos y servicios en que se estructura.»

Por ello, el Estado no puede determinar cuál es el órgano de la Comunidad Autónoma que ha de ejercer una competencia, ni el rango de la norma a través del cual ha de ejercerse, ya que ello predetermina el órgano que ha de ejercer la competencia (STC 32/1983, FJ 1; STC 56/1990, FJ 26 y STC 62/1990, FJ 1044).

Esta competencia impide la inserción forzosa en el seno de la administración autonómica de un órgano jerárquicamente dependiente de la Administración del Estado.

Así lo ha entendido el Tribunal Constitucional en su Sentencia 227/1988, de 29 de noviembre, FJ 21 c), al considerar que el art. 16.1 c), de la Ley de Aguas que creaba el delegado del Gobierno en la Administración hidráulica de las Comunidades Autónomas, vulnera la competencia para organizar su propia administración, el derecho a la autonomía de las nacionalidades y regiones, y la capacidad de organizar libremente sus propias instituciones al imponer una prescripción orgánica específica a la Administración autonómica, proclamando que:

«Resulta, en cambio, enteramente atendible la impugnación del apartado c) de ese mismo art. 16.1, que crea la figura de un delegado del Gobierno en la Administración hidráulica de las Comunidades Autónomas con la misión de asegurar la comunicación entre esta última y los organismos correspondientes de la Administración del Estado. De este modo, la Ley impone una prescripción orgánica específica a la Administración autonómica, que vulnera directamente las competencia asumida por todas las Comunidades Autónomas para organizar su propia administración. Pues, no habiendo duda de que esta potestad de autoorganización administrativa se halla limitada por la competencia del Estado sobre las bases del régimen jurídico de las Administraciones Públicas (art. 149.1.18 de la Constitución), es también evidente que este título competencial del Estado no es bastante en ningún caso para legitimar la inserción forzosa en el seno de la Administración autonómica de un órgano jerárquicamente dependiente de la Administración del Estado, pues a ello se opone de raíz el derecho de todas las nacionalidades y regiones a la autonomía (arts. 2 y 147 de la Constitución), cuya más genuina expresión es la capacidad de autoorganizarse libremente, con respeto a los mandatos constitucionales.

44 Salvo que la Constitución disponga lo contrario como sucede en su artículo 152.1 que remite a la LOPJ supuesto que se plantea en ésta y la anterior sentencia. 
(...) La mera previsión legal de dicha figura organizativa conculca las competencias que las Comunidades Autónomas tienen para organizar sus libremente sus propias instituciones.»

Esta potestad de creación de entes se extiende incluso sobre la actividad técnica e instrumental relacionada con las competencias de la Comunidad Autónoma, cual es el caso de la cartografía que ha permitido la creación del Instituto Cartográfico de Cataluña ${ }^{45}$

El alto tribunal proscribe la atribución impuesta por una ley estatal a órganos de la Administración autonómica, esto es, la injerencia competencial en un órgano interno de esta Administración. De esta manera, proscribe la exigencia impuesta por una Ley estatal de la conformidad para declarar zonas de interés para cultivos marinos de organismos de la Administración autonómica, al considerar que invade la potestad de autoorganización de las Comunidades Autónomas y vulnera el art. 148.1.1. ${ }^{\circ}$ de la Constitución, amén del art. 27.1 del Estatuto de Autonomía de Galicia ${ }^{46}$.En consecuencia, proclama el alto tribunal que la atribución a un órgano interno de la Comunidad Autónoma (una consejería) de una competencia propia y del control del cumplimiento de las disposiciones emanadas en su ejercicio ${ }^{47}$, cae dentro de la facultad de organización de sus instituciones de autogobierno.

Nótese que, en algunas sentencias, para preservar las competencias exclusivas de autoorganización de la Comunidad Autónoma sobre de su Administración propia, el Tribunal invoca el título competencial autonómico de organización de las instituciones de autogobierno aunque en puridad las Administraciones de las Comunidades no lo son.

\section{b) La competencia compartida}

Fuera de este ámbito estamos ante una competencia compartida en la que el Estado podrá dictar las bases del régimen jurídico de las Administraciones públicas y las Comunidades Autónomas podrán dictar las normas complementarias. Esto es lo que proclama la Sentencia, de constante referencia, 50/1999, en su FJ 3, con estas palabras:

«Sin embargo también hemos reiterado desde la STC 32/1981, fundamento jurídico $6^{\circ}$, que fuera desde este ámbito de actividad autonómica exclusiva, el Estado puede establecer, desde la competencia sobre las bases del régimen jurídico de las Administraciones públicas del art. 149.1.18 CE, principios y reglas básicas sobre aspectos or-

\footnotetext{
45 STC 76/1984, FJ 1. Sobre la competencia como principio delimitador de la potestad organizatoria y por ello como límite a la potestad de autoorganización de las Comunidades Autónomas ,véase el libro de ÁLVAREZ Rico, M., Principios constitucionales de organización de las Administraciones públicas, Dykinson, Madrid, 1997, pág 55 y ss.

46 STC 103/1989, FJ 7 e).

47 STC 86/1993, FJ 2.
} 


\title{
LA POTESTAD ORGANIZATORIA DE LAS COMUNIDADES AUTÓNOMAS
}

\begin{abstract}
ganizativos y de funcionamiento de todas las Administraciones públicas. Esto significa que, en palabras de la STC 227/1988, "la potestad organizatoria (autonómica) (...) para determinar el régimen jurídico de la organización y funcionamiento" de su propia Administración, no tiene carácter exclusivo, sino que debe respetar y, en su caso desarrollar las bases establecidas por el Estado. En definitiva, salvo en lo relativo a la creación de la propia Administración, la potestad de autoorganización, incluso en lo que afecta a los aspectos de organización interna y de funcionamiento no puede incluirse en la competencia exclusiva de autoorganización de las Comunidades Autónomas, aunque ciertamente, como veremos de inmediato, no cabe atribuir a las bases estatales la misma extensión e intensidad cuando se refieren a aspectos meramente organizativos internos que no afectan directamente a la actividad externa de la administración y a los administrados, que en aquellos aspectos en los que se da esta afectación».
\end{abstract}

\section{a') Las bases}

Pero estas bases según la doctrina ya señalada sólo podían regular principios generales y comunes para todas las Administraciones públicas. Pues bien, el Tribunal ha proclamado en la tan repetida Sentencia FJ 3, en la línea apuntada por la buena doctrina, que las bases han de establecer «principios y reglas básicas sobre aspectos organizativos y de funcionamiento de todas las Administraciones públicas» $\mathrm{o}$ «los elementos esenciales que garanticen un régimen jurídico unitario aplicable a todas las Administraciones Públicas» y que por ello, «debe entenderse que excede de lo básico toda aquella ordenación que por su minuciosidad y detalle, no deja espacio alguno a la competencia autonómica de desarrollo legislativo, produciéndose en tal caso, por regla general, un resultado de vulneración competencial que priva a lo presentado como básico de su condición de tal.

Es más, y aquí se produce una novedad y una matización importante en la Sentencia en favor de los poderes de autoorganización administrativa de las Comunidades Autónomas: estas bases estatales han de tener menor extensión e intensidad si se refieren a aspectos organizativos internos que no afecten directamente a la actividad externa de la Administración y los administrados, y mayor extensión e intensidad en aquellos aspectos en los que se da esta afectación, ya que el objetivo fundamental de las bases, en virtud de lo previsto en el art. 149.1.18. ${ }^{\text {a }}$ de la norma fundamental, es el de «garantizar a los administrados un tratamiento común ante ellas»:

«En virtud de esta competencia básica el Estado puede establecer los elementos esenciales que garanticen un régimen jurídico unitario aplicable a todas las Administraciones públicas. Con todo, es cierto que, como queda dicho, la intensidad y extensión que pueden tener las bases no es la misma en todos los ámbitos que integran ese régimen jurídico. Así, el alcance de lo básico será menor en aquellas cuestiones que se refieren primordialmente a la organización y al funcionamiento interno de los órganos de las Administraciones públicas, que en aquellas otras que inciden más directamente en su actividad externa, sobre todo cuando afectan a la esfera de derechos e intereses de los 
administrados, aunque ciertamente no cabe trazar una distinción tajante entre unos aspectos y otros. No debe olvidarse que, según establece el art. 149.1.18 CE, el objetivo fundamental, aunque no único, de las bases en esta materia es el de garantizar "a los administrados un tratamiento común ante ellas" y no cabe duda de que cuanto menor sea la posibilidad de incidencia externa de las cuestiones reguladas por los preceptos impugnados, más remota resultara la necesidad de asegurar ese tratamiento común y, por el contrario, mayor relieve y amplitud adquirirá la capacidad de las Comunidades Autónomas de organizar su propia Administración según sus preferencias»

\section{b') Las normas complementarias}

Las Comunidades Autónomas tienen un amplio margen de libertad de decisión para desarrollar las bases. Efectivamente, las Comunidades Autónomas tendrán que «respetar, y en su caso, desarrollar las bases establecidas por el Estado»(STC 50/1999, FJ 3) pero «para el desarrollo de estas normas básicas, las Comunidades Autónomas disponen de un amplio margen de libertad de decisión que les permite sin duda expresar sus propias opciones políticas sobre la organización administrativa que de ellas depende» (STC 227/1988 FJ 21). Por ello, la Comunidad de Madrid puede regular la composición de su Jurado territorial de expropiación forzosa al respetar los arts. 22 a 27 de la Ley 30/1992, de 26 de noviembre ${ }^{48}$.

\section{La doctrina más específica}

Junto a esta doctrina general y de síntesis el Tribunal Constitucional ha ido decantando una doctrina más específica en los campos de la función pública y la Administración de las Comunidades Autónomas.

\section{a) Función pública}

A este respecto el Tribunal Constitucional ha proclamado que de la competencia «bases del régimen jurídico de las Administraciones públicas y del régimen estatutario de sus funcionarios» deriva una competencia estatal para regular los aspectos básicos de la relación de servicios y los aspectos esenciales de la organización burocrática ${ }^{49}$. Idea en la que insiste la Sentencia 165/86, FJ 6:

«No cabe entender que la potestad de autoorganización pueda extenderse hasta abarcar en su seno la organización de la respectiva Administración pública y el régimen estatutario de sus funcionarios.

En cuanto al artículo 35, este precepto otorga a la Comunidad una competencia más específica que la que resulta del artículo 22.1, al establecer que corresponde a

\footnotetext{
48 SSTC 251/2006, de 25 de julio, FJ 7, 8, 9 y 10; 313/2006, de 8 de noviembre, FJ 4; y 314/2006, de 8 de noviembre, FJ 4.

49 STC 76/ 1983, de 5 de agosto, FJ 38.
} 


\section{LA POTESTAD ORGANIZATORIA DE LAS COMUNIDADES AUTÓNOMAS}

aquella la creación y estructuración de su propia administración pública dentro de los principios generales y normas básicas del Estado. De tal precepto estatutario cabe deducir, en efecto, que la Comunidad Autónoma de Cantabria puede conformar libremente la estructura orgánica de su aparato administrativo e incluso dictar normas que afecten a la relación orgánica que liga a los funcionarios públicos con el citado aparato, con las consiguientes potestades de dirección o jerarquía. Pero, sin embargo, no puede derivarse de ella la competencia para la relación de servicio y el régimen estatutario de sus funcionarios, pues, aun cuando esta materia esté vinculada a la estructura de la Administración autonómica, posee una naturaleza claramente diferenciable de las cuestiones estrictamente organizativas»

b) La Administración de las Comunidades Autónomas.

En cuanto a la organización de la Administración de las Comunidades Autónomas al objeto de preservar la potestad organizatoria de las Comunidades Autónomas el máximo intérprete de la Constitución proclama que nada impide que la Comunidad Autónoma disponga de un órgano, el Gabinete para Asuntos relacionados con las Comunidades Europeas, encargado de coordinar actividades que tengan una proyección exterior ${ }^{50}$.

En cambio, entiende el alto tribunal que no cabe aceptar como título competencial habilitante la organización de las instituciones de autogobierno para impedir la regulación estatal sobre Cámaras Agrarias, en la medida que participan de la naturaleza de Administraciones Públicas ${ }^{51}$; ni viola el principio de autoorganización administrativa de las Comunidades Autónomas, la previsión de un Delegado permanente estatal, designado por el Ministerio de Economía y Hacienda, que no se integra en la Administración propia de la Comunidad Autónoma, sino en un órgano exterior a la misma: el Comité directivo de cada Feria comercial Internacional ${ }^{52}$; que la consulta preceptiva al Consejo de Estado por parte de las Comunidades Autónomas no significa insertar un órgano de la Administración del Estado en el esquema organizativo de las Comunidades Autónomas que vulnera su potestad de autoorganización, al tratarse de un órgano dotado de independencia funcional ${ }^{53}$ y que la referencia que realiza una ley estatal que tiene carácter supletorio a los "órganos competentes" no vulnera la potestad autoorganizatoria prevista en el art. 148.1.1. ${ }^{\mathrm{a}}$ de la Constitución ${ }^{54}$.

Esta potestad organizatoria permite la creación y composición de los Jurados territoriales de expropiación forzosa como ya hemos visto e incluso alcanza

\footnotetext{
50 STC 165/1994, FJ 8.

51 STC 132/1989, FJ 21.

52 STC 13/1988, FJ 6.

53 STC 204/1992,FJ 2.

54 STC 103/1989, FJ 4.
} 
al Consejo Asesor de Radio Televisión Española en Cataluña, aunque sea un órgano de otra Administración, que forma parte de un ente público estatal, integrado en su estructura jerárquica y organizativa, ya que al tratarse de un órgano de integración, representativo de los intereses de la Comunidad Autónoma, ésta en virtud de lo dispuesto en los arts. 2.3 y 14 de la Ley 4/1980, de 10 de enero, del Estatuto de la Radio y la Televisión y las competencias de desarrollo normativo y ejecución de la Comunidad Autónoma, tiene el poder de corregulación en el plano organizativo o competencia compartida en virtud del cual puede regular la composición del Consejo Asesor y nombrar sus miembros dentro del marco de la Ley estatal ${ }^{55}$.

\section{EVOLUCIÓN DEL EJERCICIO DE LA POTESTAD DE AUTOORGANIZACIÓN}

\section{El punto de inicio: Los primeros Estatutos}

Entre el año 1979 y 1983 se aprueban los Estatutos de autonomía. Estos primeros Estatutos se caracterizan por un doble modelo: el modelo de las Comunidades Autónomas que accedieron al autogobierno por la vía del artículo 151 de la Constitución que de conformidad a lo dispuesto en el art. 152 incorporan las instituciones descritas en el mismo sin limitación alguna y el modelo de las Comunidades Autónomas que accedieron al autogobierno por la vía del artículo 1143 de la Constitución.

En cuanto al primer modelo, el estatuto vasco además de conformidad a lo establecido en la disposición adicional primera de la Constitución, incluye a los Territorios Históricos dentro de los poderes de la Comunidad Autónoma ${ }^{56}$, reconoce a éstos el derecho a conservar, restablecer y actualizar su organización e instituciones privativas ${ }^{57}$ y proclama su competencia exclusiva en materia de organización, régimen y funcionamiento de sus propias instituciones ${ }^{58}$; el estatuto catalán ordenaba la creación por Ley de un organismo de carácter consultivo y creaba la Sindicatura de Cuentas ${ }^{59}$.

En cuanto al segundo modelo, el Informe de la Comisión de Expertos sobre Autonomías preveía restricciones en punto a la autoorganización de las Comunidades Autónomas que se concretaban en el ejecutivo (entre las que cabe destacar que no pudieran disolver a la Asamblea legislativa y que el número de

\footnotetext{
55 STC 10/1982, de 23 de marzo, FJ 3, 4 y 9.

56 Arts. 24.2 y 37 del Estatuto.

57 Art. 3 del Estatuto.

58 Arts. 37 del Estatuto.

59 Arts. 41 y 42 del Estatuto.
} 
miembros no fuera superior a diez) y en el legislativo (períodos de sesiones limitados temporalmente o que los miembros sólo percibirían dietas) ${ }^{60}$. Estas restricciones fueron incorporadas a los Acuerdos Autonómicos de 31 de julio de $1981^{61}$ y pasaron a los Estatutos aprobados por la vía del art.143 de la Constitución. Pese a ello tampoco se puede hablar de un modelo uniforme de autoorganización ya que dentro de este grupo encontramos estatutos como el de la Comunidad valenciana (1982) que amén de las instituciones del art. 152.1 de la Constitución ya contemplan un síndico de agravios, un consejo de cultura, una sindicatura de cuentas y un consejo económico y social ${ }^{62}$; y otros, como el aragonés incluye el Justicia de Aragón entre los órganos institucionales de la Comunidad Autónoma ${ }^{63}$ o el balear que prevé la posibilidad de crear una institución similar a la del art. 54 de la Constitución ${ }^{64}$.

60 Véase Informe de la Comisión de Expertos sobre Autonomías, en Legislación sobre Comunidades autónomas 1, Tecnos, Madrid, 1982. págs. 437, 438,478 y 479:

— «4. La organización de las Comunidades autónomas.

(...)

Las instituciones que la Constitución permite que se doten las Comunidades autónomas (sobre todo la Asamblea legislativa y el ejecutivo o Consejo de gobierno) son precisas para la consagración de autonomías políticas efectivas. Pero de ahí a entender que las Comunidades autónomas necesitan pertrecharse del mismo aparto público de que ha dispuesto el Estado centralizado, va un largo camino que no debe reconocerse en ningún caso. La moderación en la ordenación de esta parcela política de la autonomía debe imponerse y ofrecer su propio ejemplo a lo que es asimismo preciso que ocurra en la parcela puramente administrativa.

En consecuencia, los ejecutivos autonómicos regionales deberán estar integrados por un número reducido de miembros, variable desde luego, en atención a la cantidad de competencias asumidas y a la población y extensión territorial de cada Comunidad autónoma. Las Asambleas legislativas, cuya generalización le parece a la Comisión conveniente, deberán tener periodos de sesiones reducidos y sus puestos no deben ser retribuidos de forma regular y permanente, sino por dietas.»

— «9. (...) El órgano ejecutivo no podrá disolver la Asamblea en ningún caso y ésta solo mediante un voto de censura constructivo podrá sustituir a aquél»

— «12. Los periodos de sesiones de las Asambleas que en el futuro se constituyan en las Comunidades Autónomas deberán ser limitados temporalmente. Deberán aplicarse criterios restrictivos respecto al número de miembros. Estos sólo percibirían dietas por su asistencia y no sueldos fijos»

- «14. Los ejecutivos regionales no deben tener un número de miembros superior a diez.»

61 Véase Acuerdos Autonómicos de 31 de julio de 1981, en Legislación sobre Comunidades autónomas, op. cit., págs. 555 y 556. Así, en cuanto al funcionamiento de las Asambleas se acordaba que «los períodos ordinarios de sesiones comprenderán cuatro meses y se celebrarán entre septiembre y diciembre, el primer periodo, y entre febrero y junio el segundo»; y que « los miembros de las Asambleas sólo deberán percibir dietas, pero no consignaciones o sueldos fijos ni periódicos»; y en cuanto a los órganos de gobierno que «el Consejo de gobierno u órgano ejecutivo no podrá disolver la Asamblea, estimándose que será beneficioso para el interés general hallar un fórmula que así lo establezca en las Comunidades Autónomas ya constituidas»; y que «los Consejos de Gobierno se compondrán, como máximo, de diez miembros con cargos de responsabilidad ejecutiva».

62 Arts. 24, 25, 59 y 60 del Estatuto valenciano de 1982.

63 Arts. 12, 33 y 34 del Estatuto.

64 Art. 29 del Estatuto balear. Institución que recogen la mayoría de estatutos de todo tipo. Así art.14 del Estatuto para Galicia, art. 46 del Estatuto para Andalucía, art. 13 del Estatuto Canario. 


\section{La evolución del ejercicio de la potestad de autoorganización}

\section{A) Las reformas 1992-1994 y de finales de los noventa}

Los Acuerdos Autonómicos de 1992 no abordaron el tema de la organización de las Comunidades Autónomas ya que como es sabido se limitaron a incrementar las competencias de las que habían accedido al autogobierno por la vía del art. 143 de la Constitución (entre ellas y como principal la educación) a través de la Ley Orgánica 9/1992, de 23 de diciembre, de transferencia de competencias a las Comunidades Autónomas que accedieron a la autonomía por la vía del artículo 143 de la Constitución y la ulterior reforma de los Estatutos de Autonomía.

En cuanto a las reformas del final de la década de los 90 la evolución del ejercicio de la potestad de autoorganización vino de la mano de tres hechos. De un lado, algunas Comunidades Autónomas como el País Vasco regularon instituciones no previstas en el Estatuto como el Consejo de Relaciones Laborales, técnica que fue confirmada por el Tribunal Constitucional en la Sentencia 35/1982, de 14 de junio, al caracterizar a éste como institución de autogobierno. De otro, el Tribunal Constitucional proclamaba la constitucionalidad de los órganos superiores consultivos de las Comunidades Autónomas en su Sentencia 204/1992, de 26 de noviembre y, de una forma implícita, la constitucionalidad de los órganos de control externo de éstas en las Sentencias 187/1988, de 17 de octubre y 18/1991, de 31 de enero. Por último, a finales de la década de los noventa se produce una nueva oleada de reformas de los Estatutos que habían accedido al autogobierno por la vía del art. 143 de la Constitución que supone la asunción de nuevas competencias, pero también la supresión de las restricciones organizativas que los pactos de 1981 habían impuesto a las comunidades autónomas en punto al ejecutivo y al legislativo; y la estatutarización de órganos de consulta, participación y control como los órganos superiores consultivos, los órganos de control externo, los consejos económico sociales o los defensores del pueblo.

\section{B) Las reformas de 2006-2007}

Esta evolución ha alcanzado su cenit en las reformas de los Estatutos que han tenido lugar durante los años 2006 y 2007 en el sentido de incorporar, en los estatutos que no la tenían, la facultad de disolución de las asambleas legislativas, estatutarizar instituciones que ya existían, regular con más detalle la organización y funcionamiento de instituciones que ya existían e incorporar instituciones nuevas.

La reforma valenciana ${ }^{65}$ incorpora la disolución de la Cámara por parte del Presidente 66 ; crea el Consell de la Justicia de la Comunitat Valenciana, cuya

65 Sobre la reforma valenciana en cuanto a la autorganización véase el artículo de ALONSO MAS, M. ${ }^{\mathrm{a}}$ J., «Las restantes competencias administrativas-1.La organización», publicado en el libro Comentario al Estatuto de Autonomía de la Comunidad Valenciana, (Dir) José M. a Baño León, Civitas, Madrid, 2007, pág. 531 y ss.

66 Art. 28.4 del Estatuto. 
estructura, composición nombramiento y funciones determinará una ley autonómica de acuerdo con lo dispuesto en la Ley Orgánica del Poder Judicial ${ }^{67}$; regula con más detalle y rigor instituciones ya contempladas en el estatuto de 1982 como son el Síndic de Greuges, la Sindicatura de Comptes, El Consell Valencia de Cultura y el Comité Econòmic i Social, incorpora en el Estatuto instituciones de relevancia estatutaria como son L'Acadèmia Valencia de la Llengua y el Consell Jurídic Consultiu que habían sido creadas por Ley tras la aprobación del primer Estatuto; clasifica a las mismas en instituciones comisionadas por las Cortes e instituciones consultivas y normativas, incluye a todas estas entidades en un nuevo capítulo VI del Título II, y dispone que el desarrollo legislativo de estas instituciones requerirá un quórum reforzado de una mayoría de tres quintas partes de la Cámara ${ }^{68}$.

La reforma catalana apunta seis novedades:

1. En su art. 2.3 interioriza a los entes locales en el sistema institucional de la Generalitat al establecer que «los municipios, las veguerías, las comarcas y los demás entes locales que las leyes determinen, también integran el sistema institucional de la Generalitat, como entes en los que ésta se organiza territorialmente, sin perjuicio de su autonomía», y regula los municipios, veguerías y comarcas en el Capítulo IV (intitulado el Gobierno local) del Título II del Estatuto referido a las instituciones.

2. Proclama en su art. 5 que el autogobierno de Cataluña se fundamenta también en los derechos históricos, en sus instituciones seculares y a la tradición jurídica catalana que el Estatuto incorpora y actualiza, de los que deriva el reconocimiento de una posición singular de la Generalitat en el sistema institucional en que se organiza.

3. Realiza una regulación más detallada de las instituciones de autogobierno a las que se refiere el art. 152.1 de la Constitución, esto es del Parlamento, Presidente de la Generalitat y Gobierno ${ }^{69}$. Pero aunque el Estatuto realiza una descripción muy detallada de las materias y las submaterias no asume explícitamente la tradicional competencia exclusiva sobre la organización de las instituciones de autogobierno.

4. Fija las disposiciones generales, los principios de organización y funcionamiento de la Administración de la Generalitat ${ }^{70}$, lo que constituye una novedad si tenemos en cuenta que el anterior Estatuto no la mencionaba y estatutariza la Comisión Jurídica Asesora y el Consejo de Trabajo, Económico y

\footnotetext{
67 Art. 33.3 del Estatuto.

68 Art..44.5 del Estatuto valenciano.

69 En sus arts. 55 y ss.

70 Arts. 71 del Estatuto.
} 
Social de Cataluña, órganos consultivos del Gobierno, remitiendo a sendas leyes para que regulen su composición y funciones ${ }^{71}$.

5. En el Capítulo V del Título II regula con detalle las funciones, composición y funcionamiento del Consejo de Garantías Estatutarias; las funciones y relaciones con otras instituciones, designación y estatuto del Síndic de Greuges; las funciones y relaciones con el Tribunal de Cuentas, composición, funcionamiento y estatuto personal de la Sindicatura de Cuentas y con menor detalle regula el Consejo Audiovisual de Cataluña.

6. Crea el Consejo de Justicia de Cataluña regulando con detalle sus atribuciones, composición, organización y funcionamiento y describe con detalle las competencias de la Generalitat sobre la Administración de justicia entre las que destacan las competencias sobre los medios personales, materiales, demarcación, planta y capitalidad judiciales ${ }^{72}$.

La reforma andaluza ${ }^{73}$ mantiene la competencia exclusiva de la Comunidad Autónoma sobre la organización y estructura de las instituciones de autogobierno, que incluye las normas y procedimientos electorales para su constitución, en el marco del régimen electoral general ${ }^{74}$. Siguiendo el modelo catalán regula con mayor detalle las instituciones de autogobierno clásicas como son el Parlamento, el Presidente y el Consejo de Gobierno, y con menor las que denomina otras instituciones de autogobierno (Defensor del Pueblo Andaluz, Consejo Consultivo, Cámara de Cuentas, Consejo Audiovisual de Andalucía y Consejo Económico y Social), instituciones que integran o forman parte de la Junta de Andalucía; regula los principios básicos de la Administración de la Comunidad Autónoma, el Consejo de Justicia de Andalucía y las competencias de la Junta en materia de Administración de Justicia ${ }^{75}$.

Mención especial merece la reforma balear respecto a la autoorganización ya que se trata de la más profunda de todos los estatutos reformados. En efecto, además de incorporar la disolución del Parlamento por parte del Presidente, y de prever la creación de un Consejo de Justicia siguiendo el modelo del Estatuto valenciano ${ }^{76}$, lo más característico de la reforma consiste en que incorpora,

71 En su art. 72.

72 Arts. 97 a 109 del Estatuto.

73 Sobre la reforma andaluza en punto a la autorganización véase el libro escrito por varios autores y dirigido por Manuel José TEROL BECERRA, La reforma del estatuto de autonomía para Andalucía. Las instituciones de la Comunidad Autónoma de Andalucía. El Poder Judicial, Instituto Andaluz de Administración pública, Sevilla, 2007. El Título IV del nuevo Estatuto ha sido comentado por Cámara Villar, G, en el capítulo VIII del libro publicado por diversos autores y coordinado por Francisco BALAGUER CALLEJón, El nuevo Estatuto de Andalucía, Tecnos, Madrid, 2007, pág. 101 y ss.

74 Art. 46 del Estatuto.

75 Arts. 99 a 155.

76 Art. 96 del Estatuto. 
racionaliza, blinda y potencia el modelo organizativo de los Consejos Insulares que ya anunciaba la Ley de Consejos Insulares del año 2.000, al introducir las siguientes novedades:

1. La Comunidad asume como primera competencia y con el carácter de exclusiva la «organización, régimen y funcionamiento de sus instituciones propias en el marco de este Estatuto ${ }^{77}$ »

2. Los Consejos han pasado a formar parte del sistema institucional autonómico, son instituciones propias de la Comunidad Autónoma, al mismo nivel que el Parlamento, el Presidente y el Gobierno ${ }^{78}$; por su posición y sus competencias, en especial la potestad reglamentaria prevista en los arts. 58.3 y 72.1 del Estatuto, han pasado a ser, en mi opinión, instituciones de autogobierno ${ }^{79}$, sin perjuicio de mantener su autonomía y su naturaleza local ${ }^{80}$, por lo que mantienen su carácter bifronte.

3. El Estatuto directamente regula la organización de los Consejos de Mallorca, Menorca e Ibiza (que es muy parecida a la de la Comunidad Autónoma), integrada por un Pleno, que adopta las decisiones más trascendentales al ejercer la iniciativa legislativa, la función normativa, elige y cesa al Presidente y controla la acción del Consejo Ejecutivo; el Presidente, que designa y separa libremente a los miembros del Consejo Ejecutivo y dirige el gobierno y la administración insulares, y el Consejo Ejecutivo integrado por el Presidente, los vicepresidentes y los consejeros ejecutivos. Regulación inicial que será desarrollada

77 Art. 30.1 de la Ley Orgánica 1/2007, de 28 de febrero, de reforma del Estatuto de Autonomía de las Illes Balears.

78 Art. 39 del Estatuto.

79 Véase mi artículo, «La posició dels Consells Insulars: organització i competències», en el libro Els consells insulars en l'Estatut d'autonomia de les Illes Balears, Responsa I, Lleonard Muntaner, Palma, 2007, pág. 121. No olvidemos que la potestad reglamentaria es consecuencia de la autonomía política, de amplias facultades de autogobierno, como ha señalado el Tribunal Constitucional en la Sentencia 108/1986, de 29 de julio, FJ 24, aunque referida a los órganos de gobierno de las Comunidades Autónomas; o manifestación de la actividad de dirección política, según la Sentencia del Tribunal Supremo de 24 de abril de 1995, FD. 3, si bien referida a la potestad reglamentaria del Gobierno proclamada en el art. 97 de la Constitución; por lo que en palabras de POMED SÁnCHEZ, L., en «Las potestades normativas del Gobierno de Aragón», en el libro Estudio sistemático de la Ley del Presidente y del Gobierno de Aragón, Cortes de Aragón, Zaragoza 1997, págs. 237 a 339, se trataría de una facultad connatural o un poder consustancial a la acción de gobierno.

80 Así el art. 39 señala que «El sistema institucional autonómico está integrado por el Parlamento, el Gobierno; el Presidente de la Comunidad Autónoma y los Consejos Insulares de Mallorca, Menorca, Ibiza y Formentera sin perjuicio de su autonomía constitucionalmente garantizada»; el art.61.3 dispone que los Consejos Insulares también son instituciones de la Comunidad Autónoma; el 62 preceptúa que los Consejos Insulares «establecerán su organización de acuerdo con la Constitución y con este Estatuto. Una ley del Parlamento regulará su organización»; los arts. 63 a 67 regulan los órganos necesarios de los Consejos de Mallorca, Menorca e Ibiza y, finalmente, el art. 68 dispone que la Ley de los Consejos Insulares aprobada con el voto favorable de los dos tercios y una ley específica para el Consejo de Insular de Formentera «determinarán las reglas de funcionamiento y el régimen jurídico de la actuación de los Consejos Insulares y de sus órganos, así como el régimen de sus funciones y competencias respetando la legislación básica del Estado». 
por la Ley de Consejos Insulares que se tendrá que aprobar, con un quórum reforzado, respetando la legislación básica del Estado ${ }^{81}$.

4. Crea un Consejo Insular nuevo, el de Formentera con unas peculiaridades en cuanto a su organización por su naturaleza de Consejo-Ayuntamiento de un municipio-isla ${ }^{82}$ y al procedimiento de transferencia de competencias ${ }^{83}$.

Menos innovadora es la reforma del Estatuto aragonés de la que destaca la disolución de las Cortes por parte del Presidente, la estatutarización del Consejo Consultivo, la calificación de la Administración Pública aragonesa como administración ordinaria en el ejercicio de sus competencias, así como la descripción de una serie de principios de organización y funcionamiento de la misma y la creación de un Consejo de Justicia siguiendo el modelo valenciano ${ }^{84}$.

Por último, la reforma del Estatuto de Castilla y León también incluye que el Presidente de la Junta puedan acordar la disolución de las Cortes, la creación de un Consejo de Justicia siguiendo el modelo valenciano y estatutariza como instituciones autonómicas propias de la Comunidad Autónoma el Consejo Económico y Social, el Procurador del Común, el Consejo Consultivo y el Consejo de Cuentas ${ }^{85}$.

\footnotetext{
81 Arts. 62 a 68 de la Ley de Reforma.

82 Arts. 63, 68 y DT 7.3 de la Ley de Reforma.

83 DT 8 de la Ley de Reforma.

84 Arts. 52, 58, 61.2, 62 у 64.

85 Arts. 18, 19, 27.1 b), 33, 37, 42, 81 y 90.
} 